\title{
BMJ Open Evaluation of the correlation between type 1 diabetes and cognitive function in children and adolescents, and comparison of this correlation with structural changes in the central nervous system: a study protocol
}

\author{
Ata Pourabbasi, ${ }^{1}$ Mehdi Tehrani-Doost, ${ }^{2}$ Soqra Ebrahimi Qavam, ${ }^{3}$ Bagher Larijani ${ }^{4}$
}

To cite: Pourabbasi A, Tehrani-Doost M, Ebrahimi Qavam S, et al. Evaluation of the correlation between type 1 diabetes and cognitive function in children and adolescents, and comparison of this correlation

with structural changes in the central nervous system:

a study protocol. BMJ Open 2016;6:e007917.

doi:10.1136/bmjopen-2015007917

- Prepublication history for this paper is available online. To view these files please visit the journal online (http://dx.doi.org/10.1136/ bmjopen-2015-007917).

Received 19 February 2015 Revised 30 November 2015 Accepted 1 December 2015

CrossMark

For numbered affiliations see end of article.

Correspondence to Dr Bagher Larijani; larijanib@tums.ac.ir

\section{ABSTRACT}

Introduction: Diabetes mellitus type 1 (T1DM) affects nearly 15 million children worldwide and failure to achieve and maintain good glycaemic control in this group can lead to diabetes-related complications. Children with T1DM can experience impairment in cognitive function such as memory, attention and executive function. This study is designed to evaluate the correlation between diabetes and cognitive dysfunction as well as to clarify whether this correlation can be linked to neurological structural changes in 6-11-year-old children with diabetes.

Methods and analysis: 310 eligible children with diabetes will be divided into two groups based on glycaemic control according to their HbA1c index. The control group will include 150 children aged 6-11 without diabetes. The following parameters will be measured and investigated: duration of the disease since diagnosis, required daily insulin dose, frequency of insulin administration, hospital admissions due to diabetes, hypoglycaemic episodes during the last year, and episodes of diabetic ketoacidosis. The following components of cognitive function will be evaluated: memory, attention, executive function, decision-making and academic performance. Cognitive function and subsequent subtests will be assessed using Cambridge Neuropsychological Test Automated Battery (CANTAB) tools. Brain structural indices such as intracranial vault (ICV), as well as cerebrospinal fluid (CSF), ventricle, hippocampus, total intracranial, total brain, grey matter and white matter volume will be measured using MRI. ANOVA, correlational tests (Spearman) and regression models will be used to evaluate the hypothesis.

Ethics and dissemination: This study is approved by the ethics committee of the Endocrinology and Metabolism Research Institute (EMRI) of Tehran University of Medical Sciences (TUMS) under reference number 00300 . Our findings are to be published in a peer-reviewed journal and disseminated both electronically and in print.

\section{INTRODUCTION}

Diabetes, one of the most common metabolic disorders, is one of the main public health concerns globally. The prevalence of diabetes varies between countries as well as between age groups. According to existing data, diabetes type 1 (T1DM) affects nearly 15 million children worldwide and its prevalence is increasing, particularly in developing countries. ${ }^{1}{ }^{2}$ Global epidemiological studies have shown the incidence of T1DM is increasing by $2-5 \%$ annually worldwide. ${ }^{3}$ In Iran, a significant prevalence of both metabolic syndrome and diabetes has been reported. ${ }^{45}$

T1DM is associated with several specific physical, psychological and social impairments in children due to their age and associated vulnerabilities. ${ }^{6}$ T1DM is the most common type of diabetes in children and sometimes requires several insulin injections per day. Consequently, children who need multiple daily injections are exposed to traumatic experiences. Many children avoid injections, which in turn, results in a high treatment failure rate in this age group. ${ }^{7} 8$ Failure to achieve and maintain good glycaemic control in children leads to diabetes-related complications such as diabetic ketoacidosis (DKA) and may be associated with serious health consequences and hospitalisation. ${ }^{9}$ This situation, in turn, results in higher levels of sensitivity to therapeutic interventions such as injections, which could further intensify psychological reactions in affected children. ${ }^{10}$

On the other hand, since cognitive function is still developing in younger patients, following a daily schedule for multiple injections is a complex task requiring parental 
assistance. This also may result in treatment failure in children with diabetes. ${ }^{11}$ Although the use of insulin pumps and techniques to reduce injection pain have improved therapeutic success and compliance in children, such treatments are not always and easily available. $^{12}$

Complications and comorbidities associated with diabetes, such as respiratory disorders and autoimmune and microvascular diseases, can lead to serious complications in children. ${ }^{13-17}$ Many diabetes-related complications are only detected after many years of exposure to high blood sugar levels. Poor glycaemic control in children due to late diagnosis could further increase the risk and intensity of such complications.

Besides the damaging effects of diabetes on various organs, cognitive changes are also very common and include changes in memory, executive function, attention and academic performance, and are among the most important impairments seen in children with diabetes. In addition to physical growth, social and emotional development is important and stimulated by formal education and schooling. Therefore, any health condition which might impact on cognitive function could, in turn, affect other areas of child development including cognitive, social and emotional development. ${ }^{18}$

The evaluation of child development and cognitive changes has been the subject of numerous studies, some of which have reported some correlations between diabetes and cognitive function. In their meta-analysis designed to evaluate diabetes and cognitive function in children, Gaudieri et $a l^{19}$ concluded that different domains of cognitive function are affected by diabetes in children. They also reported that this correlation is more prominent in patients with early onset diabetes. Children with diabetes have been shown to have lower levels of intelligence compared to children without diabetes. ${ }^{20}{ }^{21}$ In addition, Hershey and colleagues evaluated the association between hypoglycaemic episodes and memory changes in children with diabetes and showed a reduction in the spatial memory of children with T1DM. ${ }^{22}$ Executive performance is another important component of cognitive function and has been evaluated in children with diabetes in different studies. Ly $e t a t^{23}$ reported impaired executive function in children with diabetes in comparison with their healthy counterparts. In addition, changes in executive function, independent of levels of glycaemic control, have been reported in T1DM children. ${ }^{24}$

There has been much research on the association between academic performance and diabetes. ${ }^{25}$ Although the majority of studies have shown poor academic performance in children with diabetes, there are some discrepancies. For instance, whether the decline in academic performance is due to pathological changes or secondary to other consequences, such as increased absenteeism, has yet to be elucidated.

The results of several studies have clearly demonstrated that diabetes is associated with cognitive malfunction in children. However, the basic mechanism through which diabetes affects academic performance is not yet known. One suggestion is that diabetes causes academic disadvantage in children through absenteeism, which consequently results in different cognitive and learning impairments. ${ }^{26-28}$

However, other researchers believe that diabetes can induce cognitive malfunction by affecting the central nervous system (CNS) and neural structures. ${ }^{29}$ Different brain mapping studies of neural structure have demonstrated changes in the overall brain structure of patients with diabetes. ${ }^{30} 31$ These observations led to the assumption that changes in cognitive function in children with diabetes may be due to changes in neural structures. ${ }^{32}$

\section{Current study}

Previous studies designed to assess cognitive function in children with diabetes have generally focused on intelligence, memory and academic performance. Moreover, the assessment tools used in these studies differ, which in turn makes the comparison of results difficult. On the other hand, very few studies have focused on simultaneous evaluation of neural structures and cognitive function domains, especially in pre-pubertal children.

In view of the high treatment failure rates in children with diabetes, evaluation of the effects of good glycaemic control on cognitive function should be a priority, together with assessment of the preventive effects of good glycaemic control on cognitive disorders.

In view of the above arguments, the current study is designed to evaluate the correlation between diabetes and cognitive dysfunction. It aims to compare these evaluations with imaging procedures to detect neural structural changes in 6-11-year-old children with diabetes. Current available information in this age group remains sparse although cognitive changes in children with diabetes have been investigated in several studies. However, most such studies have investigated only a few aspects of cognitive function. To our knowledge, several domains of cognitive function have rarely been evaluated using a single tool and compared with structural brain changes. Therefore, in this study, we shall investigate this issue using our unique study design.

The hypotheses assessed in this study include the following (figure 1):

- Diabetes in children is associated with changes in cognitive function.

- Good glycaemic control is associated with a decrease in change in cognitive function.

- Changes in cognitive function are associated with structural changes in the brain.

- Good glycaemic control is associated with less structural changes in the brain.

Diabetes will be defined as detection of fasting blood sugar levels above $125 \mathrm{mg} / \mathrm{dL}$ measured on two occasions. Glycaemic control will be assessed using HbA1C levels. Cognitive domains to be evaluated include 
Figure 1 Research questions and hypothesis.

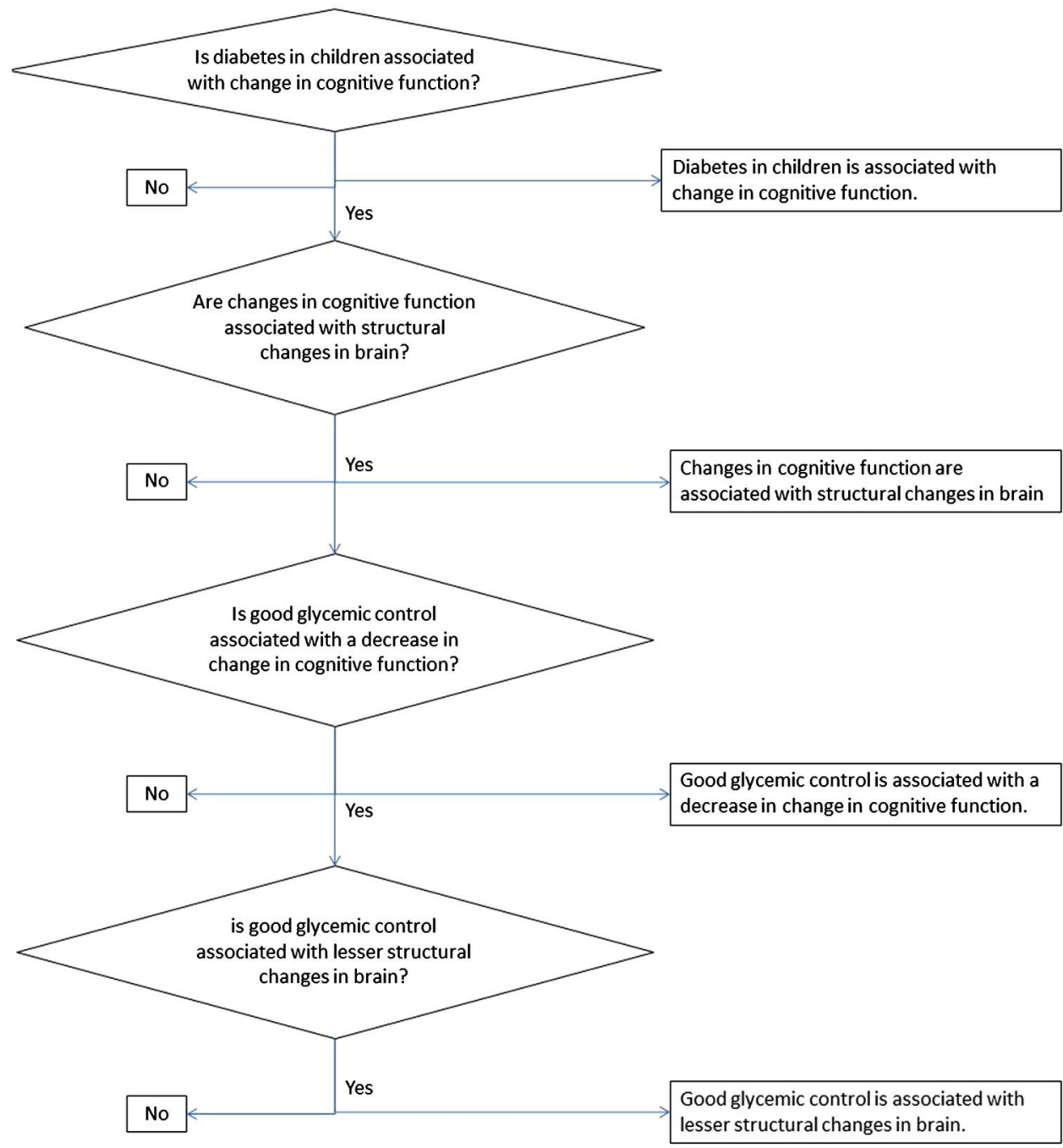

memory, attention, executive function, decision-making and academic performance. Brain structure will also be visualised and compared.

\section{METHODS AND ANALYSIS \\ Participants}

A total of 310 children with diabetes and attending the Children's Medical Center, a teaching hospital affiliated with Tehran University of Medical Sciences (TUMS) in Tehran, Iran will be enrolled in this study. The children will be between 6 and 11 years of age and from diverse socioeconomic backgrounds. One of the researchers will be present in the diabetes clinic in order to observe, discuss and enrol eligible patients into the study.

\section{Inclusion criteria}

Children aged between 6 and 11 years and diagnosed with T1DM for at least 3 months will be included. Children must live with both parents, attend regular government schools, and have no reported learning disabilities. Children with known diseases affecting the nervous system or with any history of drug consumption which might affect cognitive functions will be excluded.

\section{Sample size}

Sample size was calculated based on the equation shown in figure 2 and with $\alpha=0.05, \beta=0.2$.

Based on methods in similar studies, a standard deviation $1(\mathrm{SD} 1)=11 /$ standard deviation $2(\mathrm{SD} 2)=8 /$ difference $(D)=3$ and a sample size equal to 160 subjects in each group was estimated. ${ }^{33}$ The total number of subjects are $160 \times 3=480$.

Based on $\mathrm{SD} 1=0.31 / \mathrm{SD} 2=0.35 / \mathrm{D}=0.25$, we will randomly select 33 patients from each group for brain image assessment. Therefore, a total of 480 children in three groups (children with controlled diabetes,

$$
n=\frac{\left(z_{1-\alpha / 2}+z_{1-\beta}\right)^{2}\left(\delta_{1}{ }^{2}+\delta_{2}{ }^{2}\right)}{\left(\mu_{1}-\mu_{2}\right)^{2}}
$$

Figure 2 Sample size equation. 
children with uncontrolled diabetes, and healthy controls) will be assessed and analysed.

\section{Study groups}

Eligible children with diabetes will be divided into controlled and uncontrolled groups according to glycaemic control based on their HbAlc values. ${ }^{34}$ Under physician supervision, patients with elevated HbAlc levels and high blood sugar volatility will be allocated to the uncontrolled group. Dividing children with diabetes into controlled and uncontrolled groups will allow researchers to demonstrate any association between diabetes, cognitive function and brain structure by comparing children with uncontrolled diabetes and a healthy control group. Moreover, comparison between two groups with diabetes may demonstrate a relationship between glycaemic control, brain structure and cognitive function. All data from patients with diabetes (as a group) will be used to perform linear correlation between the glycaemic control index (HbA1c) and cognitive profiles.

Healthy control subjects will be selected from children aged 6-11 years who are referred to the emergency department of the Children's Medical Center. These children should not have any chronic diseases, must live with both parents, and should attend regular school. They should not have any gross learning disabilities, be diagnosed with diseases that affect the nervous system, or consume medications that may affect their cognitive processes. In order to minimise the effects of hospital environment and therapeutic interventions during the evaluation process, children in the control group will be assessed 1 week after admission to the emergency department. Based on a random number table, 33 of the patients enrolled in each group will be selected for an MRI scan and a briefing letter prepared by the project's director will be handed to their patients.

\section{Entering the study}

A trained researcher will visit patients in the diabetes clinic and will review their medical records under physician supervision. If a child fulfils the eligibility criteria, the researcher will discuss the study with their parents and provide them with information on the project. The researcher will also discuss the study with the child and explain the process. If the child and the parents decide to participate in the study, they will be given a consent form, which the child will also be requested to sign. Information on the brain imaging process and a separate informed consent form will also be provided to the child and their parents in case they are selected for an MRI.

\section{Measurements}

Socioeconomic status

Socioeconomic status will be assessed using a questionnaire filled out by the parents. The questionnaire will include questions about the number of children, family income, district of residence, residence status, and number of people living in the household. Diabetes duration, insulin dosage, frequency of insulin injections, hospital admission due to diabetes, hypoglycaemic episodes during the previous year, and episodes of DKA will also be determined (table 1 ).

\section{Cognitive assessment}

The child's cognitive function will be measured through assessment of: memory, attention, executive function, decision-making and academic performance (table 1). Assessment of academic performance will be performed using a questionnaire.

Cognitive function together with intra-extra dimensional set shift (IED), Stockings of Cambridge (SOC), spatial span (SSP), spatial working memory (SWM), rapid visual information processing (RVP), choice reaction time (CRT) and pattern recognition memory (PRM) will be assessed using Cambridge Neuropsychological Test Automated Battery (CANTAB) tools. ${ }^{35}$

\section{Brain mapping}

Structural mapping of the brain will be performed using a $3 \mathrm{~T}$ MRI machine in the imaging centre of Imam Khomeini Hospital. Parameters will include: repetition time $1600 \mathrm{~ms}$, time to echo $3.44 \mathrm{~ms}$, inversion time $800 \mathrm{~ms}$, flip angle 15, field of view $200 \mathrm{~mm} \times 220 \mathrm{~mm}$, matrix size $232 \times 256$, slice thickness $1.2 \mathrm{~mm}$ and in plane resolution $0.86 \mathrm{~mm} \times 0.86 \mathrm{~mm} .{ }^{33}{ }^{36} 37$ Using the obtained images, intracranial vault (ICV), cerebrospinal fluid (CSF), ventricular, hippocampus, total intracranial, total brain, grey matter and white matter volume will be analysed using a voxel-based morphometry technique (table 1).

\section{Statistical analysis}

Data related to diabetes, cognitive function and brain mapping will be collected and entered into an SPSS database for further analysis. Statistical tests such as ANOVA, correlational tests (Spearman) and regression models will be used to evaluate our hypothesis. ANOVA will be used for evaluation of quantitative statistical differences between study groups in medical, cognitive and brain structural indices. Evaluation of correlations between biological and medical indices (age, sex, age at diagnosis, treatment regimen, insulin dosage, hospital admissions, dysglycaemia), neuropsychological status (attention, memory, executive function, decision making) and brain structural indices (ICV, CSF and ventricular, hippocampus, total intracranial, total brain, grey matter and white matter volume) will be performed using correlational tests (Spearman). Regression models will be used to detect some variables as a predictive factor for neuropsychological and neurostructural changes. The statistical threshold will be set at $\mathrm{p}<0.05$ for all statistical tests. 
Table 1 Measurement tools

\begin{tabular}{|c|c|c|}
\hline & Tools & Content \\
\hline Demographics & Questionnaire & $\begin{array}{l}\text { Age, sex, family structure, family income, parents' } \\
\text { educational status, address, phone number }\end{array}$ \\
\hline $\begin{array}{l}\text { Academic } \\
\text { performance }\end{array}$ & Questionnaire & $\begin{array}{l}\text { School status (public or private), scores in literature, maths, } \\
\text { science and physical education, absenteeism }\end{array}$ \\
\hline $\begin{array}{l}\text { Medical } \\
\text { information }\end{array}$ & Questionnaire & $\begin{array}{l}\text { Duration of diagnosed DM, insulin dosage, type of insulin, } \\
\text { frequency of insulin injections, hypoglycaemic crises, DKA } \\
\text { and hospital admission in the last year, latest fasting blood } \\
\text { sugar, BS( } 2 \mathrm{HPP}), \mathrm{BUN} \text { and Cr laboratory data and trend in } \\
\mathrm{HbA} 1 \mathrm{C} \text { changes }\end{array}$ \\
\hline Cognition & $\begin{array}{l}\text { Cambridge Neuropsychological Test } \\
\text { Automated Battery (CANTAB): Intra-extra } \\
\text { dimensional set shift (IED) } \\
\text { Stockings of Cambridge (SOC) } \\
\text { Spatial span (SSP) } \\
\text { Spatial working memory (SWM) } \\
\text { Rapid visual information processing (RVP) } \\
\text { Choice reaction time (CRT) } \\
\text { Pattern recognition memory (PRM) }\end{array}$ & $\begin{array}{l}\text { Attention, working memory, verbal memory, spatial memory, } \\
\text { executive function, decision making }\end{array}$ \\
\hline Brain structure & MRI 3 Tesla & $\begin{array}{l}\text { Intracranial vault, CSF and ventricular, hippocampus, total } \\
\text { intracranial, total brain, grey matter and white matter volume }\end{array}$ \\
\hline
\end{tabular}

\section{DISCUSSION AND CONCLUSION}

Using the results of our investigations, we will seek to identify specific patterns concerning any association between diabetes, cognitive function and structural brain changes. The results of this study should show whether diabetes can affect cognitive function in children. Moreover, a comparison of cognitive function in children with poor and good glycaemic control might help researchers explain how improving diabetes control can positively affect cognitive development. Moreover, comparing the brain structures of children with and without diabetes may demonstrate possible changes in the overall brain structure of children with diabetes and show whether these changes are related to cognitive function. Comparing the brain structures of diabetic children with good and poor glycaemic control may also help demonstrate how good glycaemic control can prevent neurological changes in patients.

We chose a 6-11-year-old age group as hormonal changes caused by puberty may interfere with glycaemic control despite proper treatment. Gonder-Frederick and colleagues also selected a similar age group for evaluation of cognitive function in children with diabetes. ${ }^{38}$

Brain structural changes should be minimized through proper glycaemic control or psychological intervention. This can improve cognitive function according to the correlations between diabetes and structural brain changes may be found in our study. In light of the high rate of growth and development in the neural structure of preschoolers, the possibility of modification of neural structural changes caused by diabetes is higher in this group compared to older children.
One of the limitations of this study is that some of the components of cognitive function such as social cognition and cognitive content will not be evaluated due to the lack of appropriate tools for assessing these parameters. Moreover, more precise imaging techniques than to be used in this study may improve the accuracy of the results. Lastly, using functional imaging techniques may provide more reliable and accurate information. Nevertheless, the results of the current study may assist researchers and clinicians to design and implement more convenient medical and psychological interventions aimed at improving the cognitive function of children with diabetes.

\section{Author affiliations}

${ }^{1}$ Diabetes Research Center, Endocrinology and Metabolism Clinical Sciences Institute, Tehran University of Medical Sciences, Tehran, Iran

${ }^{2}$ Department of Psychiatry, Rouzbeh Hospital, Tehran University of Medical Sciences, Tehran, Iran

${ }^{3}$ Faculty of Psychology and Education, Allameh Tabataba'ee University, Tehran, Iran

${ }^{4}$ Endocrinology and Metabolism Research Center, Endocrinology and Metabolism Clinical Sciences Institute, Tehran University of Medical Sciences, Tehran, Iran

Acknowledgements We would like to thank Patricia Khashayar, Ali Tootee and Mona Shahrebani for their help in preparing this article.

Contributors AP: conceived and designed the study and wrote the manuscript; MT-D: conceived and designed the study, designed the methods for cognitive assessment and case selection, edited of the first draft of the paper; SEQ: conceived and designed of study, designed the methods for cognitive assessment and case selection, designed the model for analysing the neurocognitive test, edited the first draft of the paper; BL: responsible for all of the aspects of project as corresponding author. 
Funding This study is supported by the Endocrinology and Metabolism Research Institute, Tehran University of Medical Sciences, Tehran, Iran.

Competing interests None declared.

Patient consent Obtained.

Ethics approval The Board of Ethics of the Endocrinology and Metabolism Research Institute approved this study.

Provenance and peer review Not commissioned; externally peer reviewed.

Open Access This is an Open Access article distributed in accordance with the Creative Commons Attribution Non Commercial (CC BY-NC 4.0) license which permits others to distribute, remix, adapt, build upon this work noncommercially, and license their derivative works on different terms, provided the original work is properly cited and the use is non-commercial. See: http:// creativecommons.org/licenses/by-nc/4.0/

\section{REFERENCES}

1. Kliegman RM, Behrman RE, Jenson HB, et al. eds. Nelson Textbook of Pediatrics. 18th edn. Philadelphia: Saunders, 2007:2405-25.

2. Morales AE, She JX, Schatz DA. Prediction and prevention of type 1 diabetes. Curr Diab Rep 2001;1:28-32.

3. Maahs DM, West NA, Lawrence JM, et al. Epidemiology of type 1 diabetes. Endocrinol Metab Clin North Am 2010;39:481-97.

4. Ahmadi A, Gharipour M, Nouri F, et al. Metabolic syndrome in Iranian youths: a population-based study on junior and high schools students in rural and urban areas. J Diabetes Res 2013;2013:738485.

5. Ebrahimpour P, Fakhrzadeh H, Pourebrahim R, et al. Metabolic syndrome and related insulin levels in obese children. Metab Syndr Relat Disord 2006;4:172-8.

6. Oskouie F, Mehrdad N, Ebrahimi H. Mediating factors of coping process in parents of children with type 1 diabetes. J Diabetes Metab Disord 2013;12:20.

7. Cemeroglu AP, Can A, Davis AT, et al. Fear of needles in children with type 1 diabetes mellitus on multiple daily injections (MDI) and continuous subcutaneous insulin infusion (CSII). Endocr Pract 2015:21:46-53

8. Setoodeh A, Mostafavi F, Hedayat T. Glycemic control in Iranian children with type 1 diabetes mellitus: effect of gender. Indian $J$ Pediatr 2012;79:896-900.

9. Dabelea D, Rewers A, Stafford JM, et al. Trends in the prevalence of ketoacidosis at diabetes diagnosis: the SEARCH for Diabetes in Youth Study. Pediatrics 2014;133:e938-45.

10. Brod M, Kongsã, JH, Lessard S, et al. Psychological insulin resistance: patient beliefs and implications for diabetes management. Qual Life Res 2009;18:23-32.

11. Ludvigsson J, Bolli GB. Intensive insulin treatment in diabetic children. Diabetes Nutr Metab 2001;14:292-304.

12. Alsaleh FM, Smith FJ, Thompson R, et al. Insulin pump therapy: impact on the lives of children/young people with diabetes mellitus and their parents. Int J Clin Pharm 2014;36:1023-30.

13. Adlercreutz EH, Svensson J, Hansen D, et al. Prevalence of celiac disease autoimmunity in children with type 1 diabetes: regional variations across the Oresund strait between Denmark and southernmost Sweden. Pediatr Diabetes 2015;16:504-9.

14. Heimhalt-EI Hamriti M, Schreiver C, Noerenberg A, et al. Impaired skin microcirculation in paediatric patients with type 1 diabetes mellitus. Cardiovasc Diabetol 2013;12:115.

15. Martin-Frias M, Lamas A, Lara E, et al. Pulmonary function in children with type 1 diabetes mellitus. J Pediatr Endocrinol Metab 2015;28:163-9.

16. Willis CM, Batch JA, Harris M. Consistently high incidence of diabetic ketoacidosis in children with newly diagnosed type 1 diabetes. Med J Aust 2013;199:241-2.
17. Wisting L, Froisland DH, Skrivarhaug T, et al. Psychometric properties, norms, and factor structure of the diabetes eating problem survey-revised in a large sample of children and adolescents with type 1 diabetes. Diabetes Care 2013;36:2198-202.

18. Brown RT, ed. Changes in the provision of health care to children and adolescents. In: Pediatric psychology in school settings. London: Lawrence Elrbaum, 2004:1-17.

19. Gaudieri PA, Chen R, Greer TF, et al. Cognitive function in children with type 1 diabetes: a meta-analysis. Diabetes Care 2008;31:1892-7.

20. Hannonen R, Tupola S, Ahonen T, et al. Neurocognitive functioning in children with type-1 diabetes with and without episodes of severe hypoglycaemia. Dev Med Child Neurol 2003; 45:262-8.

21. Northam EA, Rankins D, Lin A, et al. Central nervous system function in youth with type 1 diabetes 12 years after disease onset. Diabetes Care 2009;32:445-50.

22. Hershey T, Perantie DC, Warren SL, et al. Frequency and timing of severe hypoglycemia affects spatial memory in children with type 1 diabetes. Diabetes Care 2005;28:2372-7.

23. Ly TT, Anderson M, Mcnamara KA, et al. Neurocognitive outcomes in young adults with early-onset type 1 diabetes: a prospective follow-up study. Diabetes Care 2011;34:2192-7.

24. Ohmann S, Popow C, Rami B, et al. Cognitive functions and glycemic control in children and adolescents with type 1 diabetes. Psychol Med 2010;40:95-103.

25. Jameson PL. Diabetes, cognitive function, and school performance. School Nurse News 2006;23:34-6.

26. Glaab LA, Brown R, Daneman D. School attendance in children with type 1 diabetes. Diabet Med 2005;22:421-6.

27. Parent KB, Wodrich DL, Hasan KS. Type 1 diabetes mellitus and school: a comparison of patients and healthy siblings. Pediatr Diabetes 2009;10:554-62.

28. Wodrich DL, Hasan K, Parent KB. Type 1 diabetes mellitus and school: a review. Pediatr Diabetes 2011;12:63-70.

29. Bober E, Buyukgebiz A. Hypoglycemia and its effects on the brain in children with type 1 diabetes mellitus. Pediatr Endocrinol Rev 2005;2:378-82.

30. Aye T, Reiss AL, Kesler S, et al. The feasibility of detecting neuropsychologic and neuroanatomic effects of type 1 diabetes in young children. Diabetes Care 2011;34:1458-62.

31. Pell GS, Lin A, Wellard RM, et al. Age-related loss of brain volume and T2 relaxation time in youth with type 1 diabetes. Diabetes Care 2012;35:513-9.

32. Kodl CT, Franc DT, Rao JP, et al. Diffusion tensor imaging identifies deficits in white matter microstructure in subjects with type 1 diabetes that correlate with reduced neurocognitive function. Diabetes 2008;57:3083-9.

33. Liane Kaufmann SP, Marc Starke, Sibylle Zotter, et al. Neurocognition and brain structure in pediatric patients with type 1 diabetes. J Pediatr Neuroradiol 2012;1:25-35.

34. Alemzadeh R, Wyatt DT. Diabetes mellitus in children. In: Kliegman RM, Jenson HB, Stanton BF, eds. Nelson textbook of pediatrics. Saunders, 2007:2404-24

35. Smith PJ, Need AC, Cirulli ET, et al. A comparison of the Cambridge Automated Neuropsychological Test Battery (CANTAB) with "traditional" neuropsychological testing instruments. J Clin Exp Neuropsychol 2013;35:319-28.

36. Chaddock L, Erickson KI, Prakash RS, et al. A neuroimaging investigation of the association between aerobic fitness, hippocampal volume, and memory performance in preadolescent children. Brain Res 2010;1358:172-83.

37. Yau PL, Castro MG, Tagani A, et al. Obesity and metabolic syndrome and functional and structural brain impairments in adolescence. Pediatrics 2012;130:e856-64.

38. Gonder-Frederick LA, Zrebiec JF, Bauchowitz AU, et al. Cognitive function is disrupted by both hypo- and hyperglycemia in school-aged children with type 1 diabetes: a field study. Diabetes Care 2009;32:1001-6. 